\title{
Prone Versus Sitting Position in Neurosurgery-Differences in Patients' Hemodynamic Management
}

\section{Luostarinen, Teemu}

2017-01

Luostarinen , T , Lindroos , A-C , Niiya , T , Silvasti-Lundell , M , Schramko , A , Hernesniemi , J , Randell , T \& Niemi , T 2017 , ' Prone Versus Sitting Position in Neurosurgery-Differences in Patients' Hemodynamic Management ' , World Neurosurgery , vol. 97 , pp. 261-266 . https://doi.org/10.1016/j.wneu.2016.10.005

http://hdl.handle.net/10138/233950

https://doi.org/10.1016/j.wneu.2016.10.005

publishedVersion

Downloaded from Helda, University of Helsinki institutional repository.

This is an electronic reprint of the original article.

This reprint may differ from the original in pagination and typographic detail.

Please cite the original version. 


\title{
Prone Versus Sitting Position in Neurosurgery-Differences in Patients' Hemodynamic Management
}

\author{
Teemu Luostarinen ${ }^{1}$, Ann-Christine Lindroos ${ }^{1}$, Tomohisa Niiya ${ }^{3}$, Marja Silvasti-Lundell ${ }^{1}$, Alexey Schramko ${ }^{1}$, \\ Juha Hernesniemi', Tarja Randell ${ }^{7}$, Tomi Niemi ${ }^{1}$
}

OBJECTIVE: Neurosurgery in general anesthesia exposes patients to hemodynamic alterations in both the prone and the sitting position. We aimed to evaluate the hemodynamic profile during stroke volume-directed fluid administration in patients undergoing neurosurgery either in the sitting or the prone position.

METHODS: In 2 separate prospective trials, 30 patients in prone and 28 patients in sitting position were randomly assigned to receive either Ringer acetate (RAC) or hydroxyethyl starch (HES; $130 \mathrm{kDa} / 0.4$ ) for optimization of stroke volume. After combining data from these 2 trials, 2-way analysis of variance was performed to compare patients' hemodynamic profile between the 2 positions and to evaluate differences between RAC and HES consumption.

RESULTS: To achieve comparable hemodynamics during surgery, a higher mean cumulative dose of RAC than HES was needed ( $679 \mathrm{~mL} \pm 390$ vs. $455 \mathrm{~mL} \pm 253 ; \boldsymbol{P}<0.05$ ). When fluid consumption was adjusted with weight, statistical difference was lost. Fluid administration did not differ between the prone and sitting position. Mean arterial pressure was lower and cardiac index and stroke volume index were higher over time in patients in the sitting position.

CONCLUSIONS: The sitting position does not require excess fluid treatment compared with the prone position. HES is slightly more effective than RAC in achieving comparable hemodynamics, but the difference might be explained by patient weight. With goal-directed fluid administration and moderate use of vasoactive drugs, it is possible to achieve stable hemodynamics in both positions.

\section{INTRODUCTION}

$\mathrm{N}$ eurosurgery performed under general anesthesia exposes patients to hemodynamic alterations (i.e., hypotension and changes in cardiac function) in both the prone and the sitting position. ${ }^{\mathrm{I}-4}$ Regarding intraoperative fluid administration, it was previously thought that colloids are superior to crystalloids in increasing intravascular volume in hypovolemic patients, but more recent findings showed that the difference might be notably smaller than was earlier believed. ${ }^{5,6}$ Similarly, a slightly better capability to improve cardiac stroke volume (SV) has been reported with colloids. ${ }^{5}$ However, more recent controversies regarding the safety of colloids safety have diminished their use. ${ }^{7,8}$

Some neurosurgical procedures can be performed in either the sitting or the prone position, but comparisons of these 2 positions are scarce in the literature. ${ }^{9}$ The aim of the present study was to compare the intraoperative requirement of 2 study fluids to achieve stable hemodynamics guided by SV measurement in neurosurgery performed in the prone versus the sitting position.

\section{MATERIALS AND METHODS}

This study consists of 2 separate patient enrollments. In the first phase, adult patients scheduled for elective primary neurosurgery in the prone position in the Department of Neurosurgery of Helsinki University Central Hospital were included. The second phase

\section{Key words \\ - Fluid administration \\ - Hemodynamics \\ - Neurosurgery \\ - Prone position \\ - Sitting position}

\section{Abbreviations and Acronyms \\ Cl: Cardiac index \\ HES: Hydroxyethyl starch \\ MAP: Mean arterial pressure \\ RAC: Ringer's acetate \\ SV: Stroke volume}

From the ${ }^{\mathbf{1}}$ Division of Anesthesiology, Department of Anesthesiology, Intensive Care and Pain Medicine, and ${ }^{2}$ Department of Neurosurgery, University of Helsinki and Helsinki University Hospital, Helsinki, Finland; and ${ }^{\mathbf{3}}$ Department of Anesthesiology, Sapporo Medical University School of Medicine, Sapporo, Japan

To whom correspondence should be addressed: Teemu Luostarinen, M.D., Ph.D. [E-mail: teemu./uostarinen@hus.fi]

Teemu Luostarinen and Ann-Christine Lindroos are co-first authors.

Citation: World Neurosurg. (2017) 97:261-266.

http://dx.doi.org/10.1016/j.wneu.2016.10.005

Journal homepage: www.WORLDNEUROSURGERY.org

Available online: www.sciencedirect.com

1878-8750/\$ - see front matter (c) 2016 Elsevier Inc. All rights reserved. 
comprised patients scheduled for elective craniotomy in the sitting position at the same institute. The Ethics Committee for Surgery of the Hospital District of Helsinki and Uusimaa approved both trials (Ethics Committee Numbers 13/13/03/04/o9 HUS and 396/E9/ 2007). Additionally, the National Agency of Medicines in Finland accepted the study protocols (EudraCT reference number 2009oo9893-28 and EudraCT reference number 2007-007106-30). All patients provided written informed consent to participate in the study.

This study uses data acquired from 2 previously executed trials: a group of patients was operated on in the prone position with SV-directed administration of study fluids and a different group of patients was operated on in the sitting position. Results of the differences between the study fluids in achieving stable hemodynamics within I surgery position and the effect these 2 fluids have on patient blood coagulation measured by thromboelastometry analysis (ROTEM, Pentafarm AG, Basle, Switzerland) have been reported earlier in 2 separate publications. ${ }^{\mathrm{IO}, \mathrm{II}}$ Exclusion criteria included age $<$ I8 years old, body mass index $>36 \mathrm{~kg} / \mathrm{m}^{2}$ in the prone position or $>40 \mathrm{~kg} / \mathrm{m}^{2}$ in the sitting position, congestive heart failure, an electrocardiogram showing other than sinus rhythm, renal failure (plasma creatinine $>\mathrm{I} 20 \mu \mathrm{mol} / \mathrm{L}$ ), hepatic failure, anemia (hemoglobin $<\mathrm{IOO} g / \mathrm{L}$ ), and thrombocytopenia (platelet count $<\mathrm{IOO} \times \mathrm{IO}^{9} /$ L). Additionally, expected use of mannitol in the sitting position resulted in exclusion.

Before anesthesia induction, a basal Ringer acetate (RAC) infusion was started at the rate of $3 \mathrm{~mL} / \mathrm{kg} /$ hour (an additional 40 $\mathrm{mmol} / \mathrm{L}$ of sodium chloride was added to RAC basal infusion of patients in the sitting position). After induction, anesthesia was maintained with sevoflurane in a mixture of nitrous oxygen and air and additional fentanyl boluses or a continuous infusion of propofol (4-Io $\mathrm{mg} / \mathrm{kg} /$ hour) and remifentanil (0.125-0.25 $\mu \mathrm{g} / \mathrm{kg} /$ $\mathrm{min}$ ) in patients operated on in the prone position and with a continuous infusion of propofol $(4-\mathrm{I} 2 \mathrm{mg} / \mathrm{kg} / \mathrm{hour}$ ) and remifentanil (0.05-0.45 $\mu \mathrm{g} / \mathrm{kg} / \mathrm{min})$ in patients operated on in the sitting position with the permission to use sevoflurane to treat severe hypertension. After tracheal intubation, volume-controlled mechanical ventilation without positive end-expiratory pressure was started (tidal volume $8-\mathrm{Io} \mathrm{ml} / \mathrm{kg}$ body weight and rate of Io$\mathrm{I} / \mathrm{min}$ ) targeting to a normoventilation (arterial carbon dioxide partial pressure, $4 \cdot 5-5.0 \mathrm{kPa}$ ).

Standard anesthesia monitoring was applied, including noninvasive blood pressure measurement before intubation, electrocardiogram, arterial saturation of oxygen, nasopharyngeal temperature, side stream spirometry (Side Stream; Datex-Ohmeda Inc., GE Healthcare, Madison, Wisconsin, USA), and end-tidal concentration of carbon dioxide. Additionally, a 20-gauge arterial catheter (Becton Dickinson and Company, Temse, Belgium) was inserted into the radial artery for invasive monitoring of arterial pressures and to obtain blood samples. To continuously monitor cardiac output, cardiac index (CI), SV, SV index, and SV variation, the Vigileo monitor (Edwards Lifesciences Corporation, Irvine, California, USA) with software version 3.02 was applied by connecting it to an arterial line with a pressure transducer set (FloTrac; Edwards Lifesciences) zeroed at the heart level. For patients operated on in the sitting position, an additional set was applied and zeroed at the level of the foramen of Monro for measurement of systolic, diastolic, and mean arterial pressure (MAP).
Both study sequences (prone and sitting position) had the same protocol for the study of fluid administration. Patients were randomly assigned (using closed envelopes drawn in sequential order by the primary investigators A-C.L. and T.N.) to receive I of the following study solutions:

I. 6\% HES solution (Voluven; Fresenius Kabi AG, Bad Homburg, Germany), 6o $\mathrm{mg} / \mathrm{mL}$, average molecular weight г30 $\mathrm{kDa}$, molar substitution ratio $0.4, \mathrm{pH} 4.0-5.5$, contents $\mathrm{Na}^{+}{ }_{154}$ $\mathrm{mmol} / \mathrm{L}$ and $\mathrm{Cl}^{-} \mathrm{I} 54 \mathrm{mmol} / \mathrm{L}$ (HES group, I5 patients in prone position and 15 patients in sitting position).

2. RAC solution (Ringer-Acetat; Fresenius Kabi AG), $\mathrm{pH}$ 6.o, contents $\mathrm{Na}^{+}$I3O $\mathrm{mmol} / \mathrm{L}, \mathrm{Cl}^{-}$II $2 \mathrm{mmol} / \mathrm{L}, \mathrm{K}^{+} 4 \mathrm{mmol} / \mathrm{L}$,

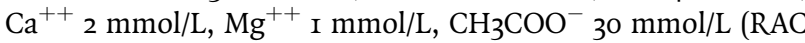
group, $\mathrm{I}_{5}$ patients in prone position and $\mathrm{I}_{3}$ patients in sitting position).

After anesthesia induction, all patients received an initial 200$\mathrm{mL}$ bolus of the study fluid over $2-4$ minutes while lying supine, and hemodynamic measurements were performed before and 3 minutes after administration of the study fluid. A new bolus of roo $\mathrm{mL}$ over $2-4$ minutes was given immediately after the hemodynamic measurements, until SV did not increase $>10 \%$. The hemodynamic measurements were performed 3 minutes after each bolus.

Thereafter, patients were positioned for surgery. Patients in the sitting position were dressed in an antigravity suit before positioning. Hemodynamic parameters were registered at 5 -minute intervals during surgery. If SV decreased $>10 \%$ from the value obtained in the supine position, further study fluid boluses of Ioo $\mathrm{mL}$ were administered. If the SV did not increase with 3 consecutive boluses, the volume expansion was stopped, and the patient was considered a nonresponder. Hemodynamic parameters were also registered at the end of surgery and after patient positioning back to supine position.

The target for MAP was $\geq 60 \mathrm{~mm} \mathrm{Hg}$ at the brain level. Boluses of phenylephrine (0.05-0.I mg) or ephedrine (5-10 $\mathrm{mg}$ ) were given if MAP was $<60 \mathrm{~mm} \mathrm{Hg}$ despite the study fluid administration. A phenylephrine or norepinephrine infusion was started whenever MAP remained $<60 \mathrm{~mm} \mathrm{Hg}$ for $>5$ minutes.

Background infusion of RAC (with $0.9 \%$ sodium chloride supplement if required) continued at the rate of $\mathrm{I} \mathrm{mL} / \mathrm{kg} /$ hour until the first postoperative morning. Urine output and fluid balance were registered at predetermined intervals.

\section{Patient Positioning}

In the prone position, bilateral chest supports were used, and the patient's head was placed on a headrest (ProneView Protective Helmet System; Dupaco, Inc., Oceanside, California, USA) or fixed with the Sugita pin head holder (Sugita Head Frames; Mizuho America, Inc., Union City, California, USA). In the sitting position, the patient's upper body was elevated $50^{\circ}-100^{\circ}$, and the head was attached to a head holder (Mayfield; Integra LifeSciences, Plainsboro, New Jersey, USA) and tilted $20^{\circ}-30^{\circ}$ forward with the patient sitting with knees slightly flexed on a pillow. For the detection of possible venous air embolism, the probe of a precordial Doppler device (Versatone D8 Perioperative Doppler; 
MedSonics, Inc., Mountain View, California, USA) was placed over the right fifth intercostal space lateral to the sternum.

\section{Statistics}

We performed this analysis post hoc by combining the data of the study fluid usage, patient hemodynamics, and basic patient demographics from the 2 previously executed trials. Two-way variance of analysis was used to test differences between the study groups (prone vs. sitting position; HES vs. RAC). When needed, a $t$ test was used to determine differences between 2 groups. Results are shown as mean \pm SD. $\mathrm{P}<0.05$ was considered statistically significant. Hemodynamic data are shown graphically as means at time points from o to 230 at 5 -minute intervals. If needed, the difference between curves could have been tested using a sign test. In all cases, the $P$ value would be $\mathrm{P} \leq$ o.0oooor.

\section{RESULTS}

After assessment of 72 patients for eligibility between August 2009 and March 20II, data from 58 patients (30 patients in prone position and 28 patients in sitting position) were analyzed. Exclusion flowcharts have been reported in conjunction with the original reports of both individual studies. ${ }^{\text {IO,II }}$

Six patients receiving RAC ( 2 in sitting position and 4 in prone position) and I patient receiving HES in prone position were considered nonresponders. The combined data show, when divided into 2 groups according to the study fluid (RAC vs. HES), that patients in the RAC group had higher weight, height, and higher body surface area. However, body mass index was equal in both groups (Table 1). Cumulative mean dose of basal RAC was similar between the study groups. When divided according to the surgery position, the groups were comparable with the exception that patients in the sitting position were younger $(\mathrm{P}<\mathrm{o.OI})$ and had higher American Society of Anesthesiologists classification $(\mathrm{P}<\mathrm{o.ooI}$ ) (Table 2$)$.

The mean cumulative dose of RAC (prone and sitting position combined) to optimize the fluid filling at 30 minutes and at end of surgery was higher than the dose of HES ( $452 \mathrm{~mL} \pm \mathrm{I} 55$ vs. 34I mL \pm Io9 and $679 \mathrm{~mL} \pm 390$ vs. $455 \mathrm{~mL} \pm 253$, respectively) (Table 3).

\section{Table 1. Patient Characteristics According to Study Fluid}

\begin{tabular}{|lccc|}
\hline Characteristic & HES & \multicolumn{1}{c|}{ RAC } & $\boldsymbol{P}$ Value \\
\hline Male/female & $6 / 23$ & $15 / 14$ & $<0.05$ \\
\hline Age (years) & $48 \pm 16$ & $48 \pm 19$ & NS \\
\hline Weight $(\mathrm{kg})$ & $73.3 \pm 12.9$ & $82.0 \pm 15.4$ & $<0.05$ \\
\hline Height $(\mathrm{cm})$ & $165.8 \pm 8.8$ & $171.6 \pm 9.3$ & $<0.05$ \\
\hline BSA (m²) & $1.83 \pm 0.18$ & $1.97 \pm 0.23$ & $<0.05$ \\
\hline ASA I/II/III/IV & $2 / 8 / 18 / 1$ & $4 / 5 / 18 / 2$ & NS \\
\hline Basal RAC (mL) & $783 \pm 218$ & $819 \pm 309$ & NS \\
\hline $\begin{array}{l}\text { Data are presented as mean } \pm \text { SD. } \\
\text { HES, hydroxyethyl starch 130 kDa/0.4; RAC, Ringer acetate; NS, not significant; BSA, body } \\
\text { surface area; ASA, American Society of Anesthesiologists. }\end{array}$ \\
\hline
\end{tabular}

Table 2. Patient Characteristics According to Surgery Position

\begin{tabular}{|lcc|c|}
\hline Characteristic & Prone & Sitting & $\boldsymbol{P}$ Value \\
\hline Male/Female & $13 / 17$ & $8 / 20$ & NS \\
\hline Age (years) & $54 \pm 18$ & $42 \pm 15$ & $<0.01$ \\
\hline Weight $(\mathrm{kg})$ & $79 \pm 15$ & $76 \pm 14$ & $\mathrm{NS}$ \\
\hline Height $(\mathrm{cm})$ & $170 \pm 8$ & $167 \pm 9$ & $\mathrm{NS}$ \\
\hline BSA $\left(\mathrm{m}^{2}\right)$ & $1.93 \pm 0.22$ & $1.88 \pm 0.20$ & NS \\
\hline ASA I/II/III/IV & $6 / 13 / 10 / 1$ & $0 / 0 / 26 / 2$ & $<0.001$ \\
\hline Ephedrine total dose (mg) & $9.2 \pm 4.9$ & $4.4 \pm 1.3$ & NS \\
\hline Phenylephrine total dose (mg) & $1.4 \pm 1.7$ & $1.4 \pm 2.3$ & NS \\
\hline $\begin{array}{l}\text { Data are presented as mean } \pm \text { SD. } \\
\text { NS, not significant; BSA, body surface area; ASA, American Society of Anesthesiologists. }\end{array}$ \\
\hline
\end{tabular}

When RAC and HES doses were adjusted with patient's weight, the mean doses at 30 minutes and at the end of surgery for RAC still remained higher than doses of HES $(5.5 \mathrm{~mL} / \mathrm{kg} \pm$ r.6 vs. $4.8 \mathrm{~mL} / \mathrm{kg} \pm \mathrm{I} .7$ and $8.2 \mathrm{~mL} / \mathrm{kg} \pm 4.2$ vs. $6.4 \mathrm{~mL} / \mathrm{kg} \pm 3.6$, respectively), but statistical significance was lost. RAC and HES doses before positioning were similar in both positions. Regarding patient positioning during surgery, the fluid consumption of study fluids did not differ between the 2 groups (Table 3). Patients in the sitting position had lower MAP over time and higher $\mathrm{CI}$ and SV index than patients in the prone position (Figure 1).

\section{DISCUSSION}

The present study shows that with goal-directed fluid administration and moderate use of vasoactive drugs, it is possible to achieve stable hemodynamics in both the sitting and the prone

\begin{tabular}{|c|c|c|c|c|}
\hline Fluid & Sitting & Prone & $\begin{array}{l}\text { Position } \\
\text { Combined }\end{array}$ & $\begin{array}{c}P \\
\text { Value }\end{array}$ \\
\hline HES total $\mathrm{mL}$ & & & $455 \pm 253$ & \\
\hline RAC total $\mathrm{mL}$ & & & $679 \pm 390$ & $<0.05^{*}$ \\
\hline Study fluids combined & $586 \pm 376$ & $550 \pm 319$ & $567 \pm 345$ & \\
\hline HES start bolus $\mathrm{mL}$ & & & $255 \pm 51$ & \\
\hline RAC start bolus $\mathrm{mL}$ & & & $266 \pm 55$ & NS \\
\hline Study fluids combined & $268 \pm 48$ & $253 \pm 57$ & $260 \pm 53$ & \\
\hline HES at 30 minutes $(\mathrm{mL})$ & & & $341 \pm 109$ & \\
\hline $\mathrm{RAC}$ at 30 minutes $(\mathrm{mL})$ & & & $452 \pm 155$ & $<0.001^{*}$ \\
\hline Study fluids combined & $396 \pm 137$ & $397 \pm 152$ & $397 \pm 144$ & \\
\hline
\end{tabular}




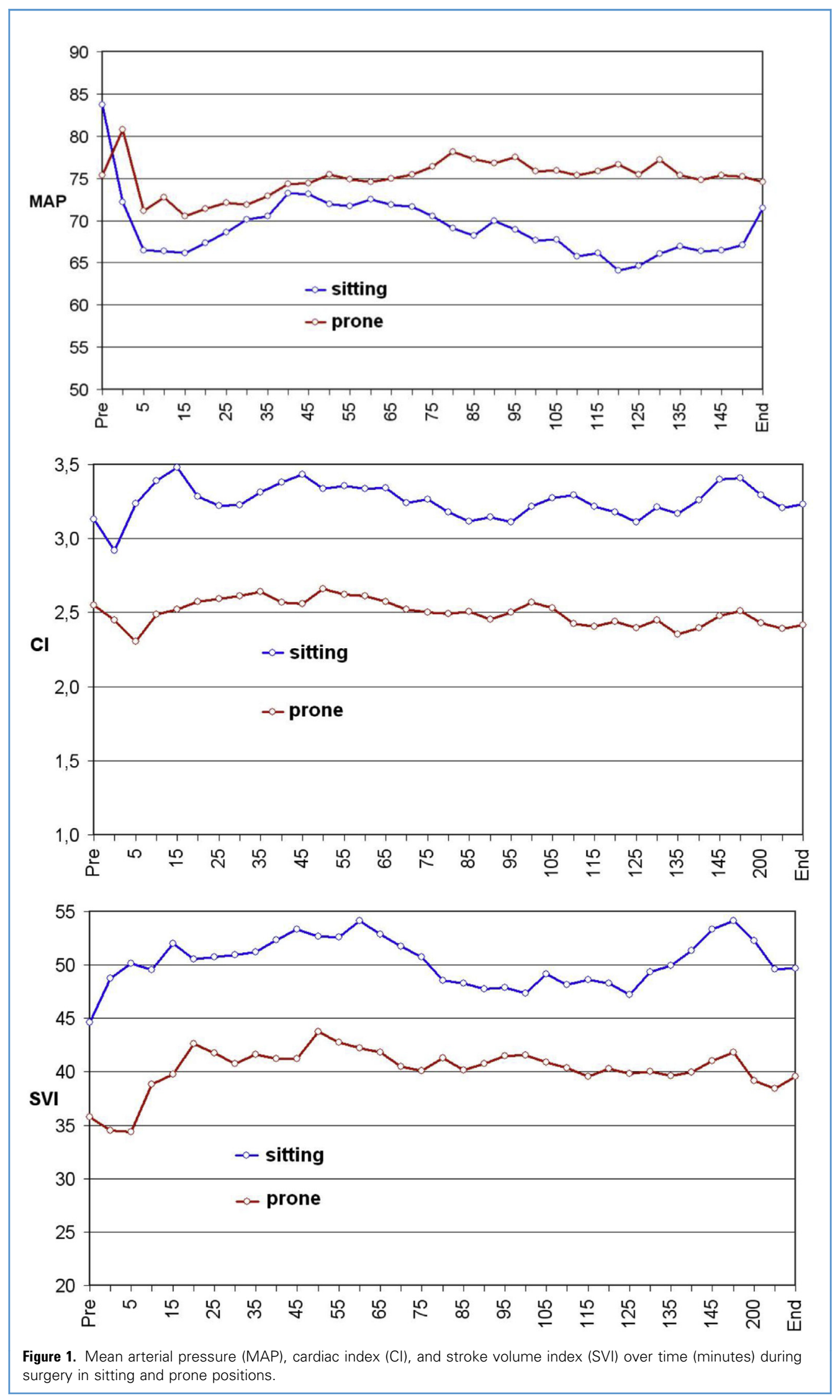


position in neurosurgery. The sitting position does not require excess intravenous fluid administration compared with surgery in the prone position. Moreover, the benefit of using HES to optimize patient hemodynamics instead of RAC is only marginal.

Neurosurgery in the sitting position was more popular in the I970s and I980s than it is today. Even today, there is a great variation in its use among the countries where the sitting position is used. ${ }^{12}$ The sitting position is still often considered preferable when operating on lesions in the posterior cranial fossa., ${ }^{9,13}$ Advantages of the sitting position are decreased intracranial pressure and a clearer operating field secondary to gravity forced downward drainage of blood and cerebrospinal fluid. Neurosurgery in the sitting position also decreases the incidence of cranial nerve damage. ${ }^{13}$ The sitting position is known to cause hypotension and decrease in cardiac function, presenting a challenge to the neuroanesthesiologist in guaranteeing sufficient cerebral blood pressure and oxygen delivery. Another concern related to the sitting position is venous air embolism, which has an incidence of $1.6 \%-50 \%$, with the incidence being lower in the semisitting position. . $, 3, \mathrm{IO}, \mathrm{I} 4-\mathrm{I} 7^{-}$

Historically, it was believed that the capability of colloids to increase intravascular volume in hypovolemic patients would be 2to 3 -fold compared with crystalloids, but more recent findings indicate that I:I to I:I.5-I.8 is the more accurate ratio., ${ }^{5,6,18} \mathrm{~A}$ similar ratio was found in patients undergoing elective neurosurgery. ${ }^{\text {IO,II }}$ Our results showed a ratio of I:I.5 between HES and RAC in achieving comparable hemodynamics, which is in line with the earlier findings. Even this might be an overestimation, because after adjustment with patients' weight, the difference between HES and RAC was reduced to I.3-fold and was no longer statistically significant.

In the present study, we demonstrated that the previously reported decrease in cardiac function when the prone position is applied can be prevented with SV-directed fluid administration and moderate use of vasoactive drugs. ${ }^{19-22}$ Moreover, with similar fluid and vasoactive drug administration, patients in the sitting position maintained good cardiac function after positioning, and decrease in cardiac function did not occur. ${ }^{\mathrm{I}}$ Although MAP remained adequate throughout the surgery, it was lower in the sitting position, confirming a tendency of hypotension in this position. Patients in the sitting position in our study wore antigravity suits, which in part prevent pooling of the blood in the lower extremities and thus help stabilize patient hemodynamics. Patients in the sitting position had a higher $\mathrm{CI}$ than patients in the prone position. This possibly reflects patients operated on in the sitting position being healthier and younger. Anesthesia was maintained with propofol in the sitting position, whereas mainly volatile anesthetics were used in the prone position. This adds to the complexity of $\mathrm{CI}$ interpretation. ${ }^{23}$

There are various methods of measuring cerebral perfusion pressure in neurosurgical patients; we measured the MAP at the level of the foramen of Monro, giving us a more accurate estimate of cerebral perfusion pressure. If MAP would have been measured at the level of the heart, the values would be $15-25 \mathrm{~mm} \mathrm{Hg}$ higher and reflect the systemic blood pressure more. ${ }^{24,25}$

Discussion about safety of artificial colloids is ongoing. Increased risk of mortality and kidney failure in critically ill patients associated with the use of HES and related consensus statements have decreased use of artificial colloids dramatically. ${ }^{7,8,26}$ Recent years have seen a plethora of reports trying to determine whether this risk is real in other patient populations as well (i.e., general surgery patients). The possible negative effect colloids have on coagulation is important to bear in mind when treating neurosurgical patients, as normal coagulation capacity in this patient population is essential. ${ }^{27}$ Although the initial filling doses of study fluids were not enough to stabilize hemodynamics before positioning, the total doses of intraoperative fluids in our study were low, and only a minor difference in doses was seen between HES and RAC. In that light, it would be difficult to recommend HES use in neurosurgical patients operated on in the sitting position.

\section{CONCLUSIONS}

Neurosurgery with the patient in the sitting position does not require excessive fluid administration compared with the prone position to achieve stable hemodynamics. The possible minor benefit gained from using HES to diminish fluid load is counteracted by the possible harm associated with the use of artificial colloids.

\section{ACKNOWLEDGMENTS}

We are grateful to Matti Kataja, Ph.D., for assistance with the statistical analysis.

\section{REFERENCES \\ I. Buhre W, Weyland A, Buhre K, Kazmaier S, Mursch K, Schmidt M. Effects of the sitting po- sition on the distribution of blood volume in pa- tients undergoing neurosurgical procedures. $\mathrm{Br} \mathrm{J}$ Anaesth. 2000;84:354-357. \\ 2. Black S, Ockert DB, Oliver WC, Cucchiara RF. Outcome following posterior fossa craniectomy in patients in the sitting or horizontal positions. Anesthesiology. I988;69:49-56. \\ 3. Matjasko J, Petrozza P, Cohen M, Steinberg P. Anesthesia and surgery in the seated position: analysis of 554 cases. Neurosurgery. I985;17: 695-702.}

4. Tsaousi GG, Karakoulas KA, Amaniti EN, Soultati ID, Zouka MD, Vasilakos DG. Correlation of central venous-arterial and mixed venousarterial carbon dioxide tension gradient with cardiac output during neurosurgical procedures in the sitting position. Eur J Anaesthesiol. 2010;27: 882-889.

5. Verheij J, van Lingen A, Beishuizen A, Christiaans HM, de Jong JR, Girbes AR, et al. Cardiac response is greater for colloid than saline fluid loading after cardiac or vascular surgery. Intensive Care Med. 2006;32:1030-1038.

6. Hartog CS, Bauer M, Reinhart K. The efficacy and safety of colloid resuscitation in the critically ill. Anesth Analg. 20II;II2:156-I64.
7. Perner A, Haase N, Guttormsen AB, Tenhunen J, Klemenzson G, Åneman A, et al. Hydroxyethyl starch 130/0.42 versus Ringer's acetate in severe sepsis. N Engl J Med. 2012;367:I24-I34.

8. Myburgh JA, Finfer S, Bellomo R, Billot L, Cass A Gattas D, et al. Hydroxyethyl starch or saline for fluid resuscitation in intensive care. $\mathrm{N}$ Engl J Med. 20I2;367:IgOI-I9II.

9. Porter JM, Pidgeon C, Cunningham AJ. The sitting position in neurosurgery: a critical appraisal. $\mathrm{Br} \mathrm{J}$ Anaesth. I999;82:II7-I28.

ı. Lindroos AC, Niiya $T$, Silvasti-Lundell $M$ Randell T, Hernesniemi J, Niemi TT. Stroke volume-directed administration of hydroxyethyl starch or Ringer's acetate in sitting position 
during craniotomy. Acta Anaesthesiol Scand. 2013;57: $729-736$.

II. Lindroos AC, Niiya T, Randell T, Niemi TT. Stroke volume-directed administration of hydroxyethyl starch (HES 130/0.4) and Ringer's acetate in prone position during neurosurgery: a randomized controlled trial. J Anesth [Internet]. 2013;28:I89-I97.

I2. Jürgens S, Basu S. The sitting position in anaesthesia: old and new. Eur J Anaesthesiol. 20I4;3I: 285-287.

I3. Feigl GC, Decker K, Wurms M, Krischek B, Ritz R, Unertl K, et al. Neurosurgical procedures in the semisitting position: evaluation of the risk of paradoxical venous air embolism in patients with a patent foramen ovale. World Neurosurg. 20I4; 8I:I59-I64.

I4. Smelt WL, de Lange JJ, Booij LH. Cardiorespiratory effects of the sitting position in neurosurgery. Acta Anaesthesiol Belg. I988;39:223-23I.

I5. Lindroos AC, Niiya TT, Randell TT, Romani RR, Hernesniemi JJ, Niemi TT. Sitting position for removal of pineal region lesions: the Helsinki experience. World Neurosurg. 2010;74:505-513.

I6. Young ML, Smith DS, Murtagh F, Vasquez A, Levitt J. Comparison of surgical and anesthetic complications in neurosurgical patients experiencing venous air embolism in the sitting position. Neurosurgery. 1986;18:157.

I7. Jadik S, Wissing H, Friedrich K, Beck J, Seifert V, Raabe A. A standardized protocol for the prevention of clinically relevant venous air embolism during neurosurgical interventions in the semisitting position. Neurosurgery. 2009;64: $533-538$.

I8. Hartog CS, Kohl M, Reinhart K. A systematic review of third-generation hydroxyethyl starch (HES I30/0.4) in resuscitation: safety not adequately addressed. Anesth Analg. 20II;II2:635-645.

I9. Edgcombe H, Carter K, Yarrow S. Anaesthesia in the prone position. Br J Anaesth. 2007;I00:I65-I83.

20. Hatada T, Kusunoki M, Sakiyama T, Sakanoue Y, Yamamura T, Okutani R, et al. Hemodynamics in the prone jackknife position during surgery. Am J Surg. I991;162:55-58.

2I. Dharmavaram S, Jellish WS, Nockels RP, Shea J, Mehmood R, Ghanayem A, et al. Effect of prone positioning systems on hemodynamic and cardiac function during lumbar spine surgery: an echocardiographic study. Spine (Phila Pa 1976). 2006;3I: I388-I394.

22. Wadsworth R, Anderton JM, Vohra A. The effect of four different surgical prone positions on cardiovascular parameters in healthy volunteers. Anaesthesia. I996;51:819-822.

23. Sudheer PS, Logan SW, Ateleanu B, Hall JE. Haemodynamic effects of the prone position: comparison of propofol total intravenous and inhalation anaesthesia. Anaesthesia. 2006;6I: I38-I4I.
24. Rosner MJ, Coley IB. Cerebral perfusion pressure, intracranial pressure, and head elevation. J Neurosurg. I986;65:636-64I.

25. Kosty JA, Leroux PD, Levine J, Park S, Kumar MA Frangos S, et al. Brief report: a comparison of clinical and research practices in measuring cerebral perfusion pressure: a literature review and practitioner survey. Anesth Analg. 2013;117:694-698.

26. Reinhart K, Perner A, Sprung CL, Jaeschke R, Schortgen F, Johan Groeneveld AB, et al Consensus statement of the ESICM task force on colloid volume therapy in critically ill patients. Intensive Care Med. 2012;38:368-383.

27. Kozek-Langenecker SA. Effects of hydroxyethyl starch solutions on hemostasis. Anesthesiology. 2005; I03:654-660.

Conflict of interest statement: The authors declare that the article content was composed in the absence of any commercial or financial relationships that could be construed as a potential conflict of interest.

Received 11 April 2016; accepted 1 October 2016

Citation: World Neurosurg. (2017) 97:261-266. http://dx.doi.org/10.1016/j.wneu.2016.10.005 Journal homepage: www.WORLDNEUROSURGERY.org Available online: www.sciencedirect.com 1878-8750/\$ - see front matter (c) 2016 Elsevier Inc. All rights reserved.

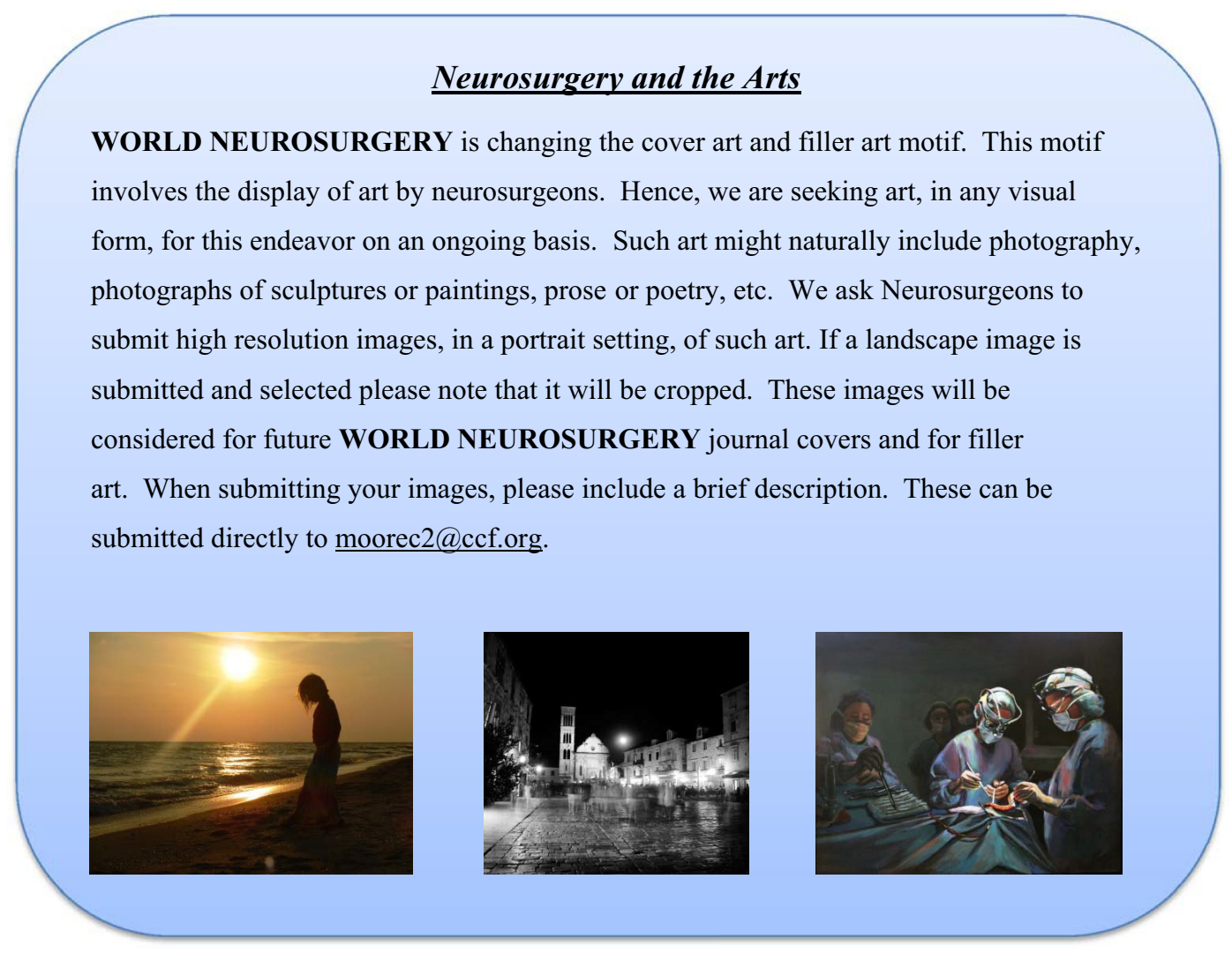

